\title{
Effect of Sn Addition on Phase Transformation Behavior of Equiatomic Ni-Ti Shape Memory Alloy
}

\author{
Ali A. Aljebouri ${ }^{1} \quad$ Safa H. Mohammed ${ }^{2}$ Mudhafar A. Mohammed ${ }^{3}$
}

\author{
1,2,3 Applied Sciences Department/ University of Technology / Baghdad/Iraq \\ ${ }^{1}$ ORCID ID: 0000-0002-1570-9739, ${ }^{2}$ ORCID ID: 0000-0002-7789-6111, ${ }^{3}$ ORCID ID: 0000-0001-8524-4714 \\ 1ajubouri1@yahoo.com, ${ }^{2}$ safa_ha_90@yahoo.com, ${ }^{3}$ dr_mothaffer@yahoo.com \\ *Corresponding author: safa_ha_90@yahoo.com, 0096407719750678
}

\section{Received 17/10/2019, Accepted 2/2/2020, Published 8/9/2020}

This work is licensed under a Creative Commons Attribution 4.0 International License.

\begin{abstract}
Sn effect on the phase transformation behavior, microstructure, and micro hardness of equiatomic NiTi shape memory alloy was studied. NiTi and NiTiSn alloys were produced using vacuum induction melting process with alloys composition ( $50 \%$ at. $\mathrm{Ni}, 50 \%$ at. Ti) and (Ni $48 \%$ at., $\mathrm{Ti} 50 \%$ at., $\mathrm{Sn} 2 \%$ at.). The characteristics of both alloys were investigated by utilizing Differential Scanning Calorimetry, X- ray Diffraction Analysis, Scanning Electron Microscope, optical microscope and vicker's micro hardness test. The results showed that adding Sn element leads to decrease the phase transformation temperatures evidently. Both alloy samples contain NiTi matrix phase and $\mathrm{Ti}_{2} \mathrm{Ni}$ secondary phase, but the $\mathrm{Ti}_{2} \mathrm{Ni}$ phase content decreases with $\mathrm{Sn}$ addition and this is one of the reasons that leads to decrease the micro hardness of alloy with adding $\mathrm{Sn}$ element in a noticeable manner. The micro hardness decreases from 238.74 for NiTi equiatomic alloy to 202 for NiTiSn alloy after heat treatment.
\end{abstract}

Key words: DSC, NiTi alloy, NiTiSn alloy, Shape memory alloys.

\section{Introduction}

$\mathrm{Ni}-\mathrm{Ti}$ shape memory alloys (SMAs) are interesting materials in engineering applications because they have shaped memory effect and superelasticity. In general, the two factors that effect on $\mathrm{Ni}-\mathrm{Ti}$ SMAs application in engineering are the phase transformation temperatures and mechanical characteristics $(1,2)$. In particular, the third alloying element addition to the binary Ni-Ti shape memory alloy plays a significant role in changing phase transformation temperatures and mechanical characteristics $(3,4)$.

The phase diagram of Ni-Ti alloy system is important for heat-treatments of the alloys and improvement of the shape memory characteristics. The research interests are restricted in the central region bounded by $\mathrm{Ti}_{2} \mathrm{Ni}$ and $\mathrm{TiNi} 3$ phases (Fig.1). Since the single phase Ni-Ti B2 near the equiatomic composition transforms into a monoclinic phase martensitically B19', as shown in Fig.1, it is clear that the boundary on Ti-rich side is close to $50 \% \mathrm{Ni}$, and is nearly vertical, while the boundary on Ni-rich side decreases with low temperature and hence the solubility decreases greatly (3).

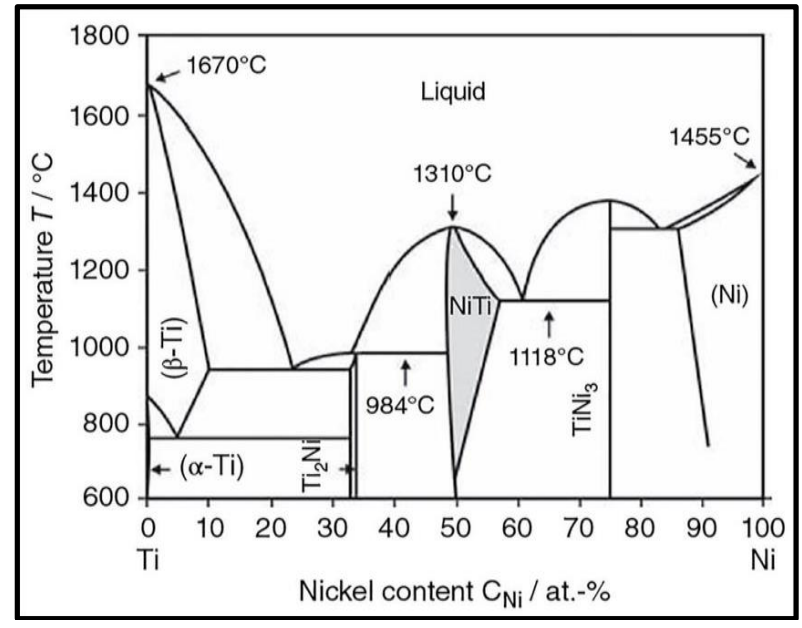

Figure1: Phase diagram of Ni-Ti alloy (3).

$\mathrm{B} 2 \rightarrow \mathrm{R}$ (austenite to R-phase) phase transformation becomes interesting in many applications, such as actuators, because of the small thermal hysteresis and high fatigue life. Different methods used to produce the phase transformation $\mathrm{B} 2 \rightarrow \mathrm{R}$ in the $\mathrm{Ni}-$ Ti SMAs, like adding a third alloying element to an 
equi-atomic $\mathrm{Ni}-\mathrm{Ti}$ shape memory alloy (5-7), grain refinement (8), thermo-mechanical treatment (9), and aging of Ni-rich alloys (10), have been developed. It's known that when $\mathrm{Al}, \mathrm{Mo}, \mathrm{Fe}, \mathrm{Co}$, and $\mathrm{Cr}(6-13)$ is added to near equi-atomic $\mathrm{Ni}-\mathrm{Ti}$ shape memory alloys, it will produce R-phase (trigonal crystal structure). $\mathrm{Co}, \mathrm{Cr}, \mathrm{Fe}$ and Mo are transition metals; $\mathrm{Al}$ is not transitioned metal with electronic configuration $[\mathrm{Ne}] 3 \mathrm{~s}^{2} 3 \mathrm{p}$. Similar to $\mathrm{Al}$, $\mathrm{Sn}$ is not a transitioning metal with electronic configuration of $[\mathrm{Kr}] 4 \mathrm{~d}^{10} 5 \mathrm{~s}^{2} 5 \mathrm{p}^{2}$. This means that to introduce the R-phase transformation in Ni-Ti shape memory alloys by adding a third alloying element, it's not necessary to add transition metals. However, the effects of adding Sn element on the martensitic phase transformation behavior of $\mathrm{Ni}-\mathrm{Ti}$ shape memory alloys are inconsistent. Some researchers have reported that the $\mathrm{B} 2 \rightarrow \mathrm{R} \rightarrow \mathrm{B} 19$ ' (austenite to Rphase to martensite) phase transformation occurred in Ti49.5Ni0.5Sn, Ti49Ni1.0Sn, and Ti48.5Ni1.5Sn alloys, while the $\mathrm{B} 2 \rightarrow \mathrm{B} 19^{\prime}$ phase transformation occurred in a Ti50.0Ni1.0Sn alloy, and it has been proved that when Sn substitutes Ni of equi-atomic Ni-Ti shape memory alloy is effective to produce Rphase transformation (14). In the present study, equiatomic NiTi and NiTiSn shape memory alloys were prepared by vacuum induction melting method. The aim of the research is investigating the effect of adding tin (Sn) element into $\mathrm{Ni}$-Ti alloy and studying their morphological, thermal and mechanical properties.

\section{Materials and method}

Titanium wire with purity 98.66 wt. \%, Nickel plate with 99.9 wt. \% purity, and tin 99.9 wt. \% were immersed in acetone and alcohol in an ultrasonic bath, and then they were washed with distilled water and dried before melting. NiTiSn alloy composition contains 48 at $\% \mathrm{Ni}, 50$ at $\% \mathrm{Ti}$ and 2 at $\% \mathrm{Sn}$ compared with equiatomic NiTi alloy containing 50 at $\% \mathrm{Ni}, 50$ at $\% \mathrm{Ti}$. The ingredient elements of these two alloys are frequently melted three times in a graphite crucible using high-frequency induction vacuum furnace under argon atmosphere. The heat treatment of the selected two samples was accomplished at $865^{\circ} \mathrm{C}$ for $15 \mathrm{~min}$ in a furnace under normal atmosphere and quenched in icy water. An optical microscope with a magnification of (4X) was used to investigate the microstructure of the samples. The samples were grinded, polished, and finally, etched using a solution of $\left(30 \mathrm{ml} \mathrm{H}_{2} \mathrm{O}\right.$, $20 \mathrm{ml} \mathrm{HNO}_{3}, 10 \mathrm{ml} \mathrm{HF}$ ) for $10 \mathrm{sec}$ to show the grain boundaries and the microstructure of alloys. For microstructure and chemical compositions, analysis of samples by "scanning electron microscope SEM" conducted with the "energy dispersive x-ray" analysis unit EDX model (VEGA3LM) were accomplished. X-ray diffraction test was carried out using a Shimadzu device; to analyse the different phases of the heat treated samples. Differential scanning calorimetry (DSC) was produced by SETARAM, type 131 EVO. A different temperature ranging from $\left(-100{ }^{\circ} \mathrm{C}-300{ }^{\circ} \mathrm{C}\right)$ with heating/cooling rate $10{ }^{\circ} \mathrm{C} / \mathrm{min}$ in liquid nitrogen atmosphere was used to determine the transformation temperatures of the selected samples. For micro-hardness measurements, the test was done at room temperature using micro-hardness Vickers tester type (Laryee model VHS-1000), under $300 \mathrm{gf}$, load for holding time of $10 \mathrm{sec}$.

\section{Results and discussion}

The heat flow curves of equiatomic NiTi and NiTiSn SMA are given in Fig.2a \&b. The R start temperature $R_{s}$, $R$ peak temperature $R_{p}, R$ finish temperature $\mathrm{R}_{\mathrm{f}}$, Austenite start temperature $\mathrm{A}_{\mathrm{s}}$, Austenite peak temperature $A_{p}$, Austenite finish temperature $\mathrm{A}_{\mathrm{f}}$, Martensite start temperature $\mathrm{M}_{\mathrm{s}}$, Martensite peak temperature $M_{p}$, Martensite finish temperature $\mathrm{M}_{\mathrm{f}}$ values and thermal hysteresis of equiatomic NiTi and NiTiSn alloys are illustrated in Table1.

Table1. The transformation temperatures $\left({ }^{\circ} \mathrm{C}\right)$ of equi-atomic binary NiTi and NiTiSn SMAs after heat treatment.

\begin{tabular}{|c|c|c|c|c|c|c|c|c|c|c|c|}
\hline \multicolumn{2}{|c|}{ Sample } & \multirow{2}{*}{$\begin{array}{l}\mathrm{R}_{\mathrm{s}} \\
14.4\end{array}$} & \multirow{2}{*}{$\begin{array}{l}\mathrm{R}_{\mathrm{f}} \\
89.5\end{array}$} & \multirow{2}{*}{$\begin{array}{l}\mathrm{A}_{\mathrm{s}} \\
100.1\end{array}$} & \multirow{2}{*}{$\begin{array}{l}A_{f} \\
137.2\end{array}$} & \multirow{2}{*}{$\begin{array}{l}\mathrm{M}_{\mathrm{s}} \\
-\end{array}$} & \multirow{2}{*}{$\begin{array}{l}M_{f} \\
-\end{array}$} & \multirow{2}{*}{$\begin{array}{l}A_{p} \\
108.46\end{array}$} & \multirow{2}{*}{$\begin{array}{l}\mathrm{M}_{\mathrm{p}} \\
-\end{array}$} & \multirow{2}{*}{$\begin{array}{l}R_{p} \\
43.98\end{array}$} & \multirow{2}{*}{$\begin{array}{l}\mathrm{TH}\left(\mathrm{A}_{\mathrm{f}}-\mathrm{M}_{\mathrm{s}}\right) \\
129.6\end{array}$} \\
\hline$\stackrel{\infty}{\Xi}$ & NiTi & & & & & & & & & & \\
\hline 疍 & NiTiSn & -57.2 & 29.2 & 56.8 & 120.3 & - & - & 91.48 & - & -11 & 86.9 \\
\hline$\stackrel{\infty}{\Xi}$ & NiTi & 39.7 & 12.7 & - & - & 7.6 & -42.6 & - & 1.35 & 19.16 & \\
\hline 8 & NiTiSn & - & - & - & - & 33.4 & -60.6 & - & -5.16 & - & \\
\hline
\end{tabular}

Fig. 2 shows the DSC profile of a) binary equiatomic NiTi and b) NiTiSn SMAs. Equiatomic binary NiTi alloy undergoing two steps transformation during heating and cooling. Two 
exothermal peaks appear during the cooling process which refers to the transformation from the austenite phase B2 to the R-phase and from R-phase to martensite phase $\mathrm{B} 19$ ', respectively. Also, two endothermal peaks are revealed during heating, which indicates the transformation from the martensite phase B19' to R-phase and from R-phase to austenite phase B2, respectively (15). The Rphase appears because of the formation of $\mathrm{Ti}_{2} \mathrm{Ni}$ coherent phase which causes the local stresses field formation (3). Also, there is a strong resistance from this precipitates to the phase transformation with large strain like, B2 $\rightarrow$ B19', while have a small resistance to phase transformation with small strain like, B2 $\rightarrow \mathrm{R}$ (3). This transformation behavior is most like that presented by Niraj N. et al. (15). In NiTiSn alloy substituting $\mathrm{Sn}$ for $\mathrm{Ni}$, there are two endothermal peaks during heating which indicate the transformation from the martensite phase to Rphase and from $\mathrm{R}$ - phase to the austenite phase, respectively.
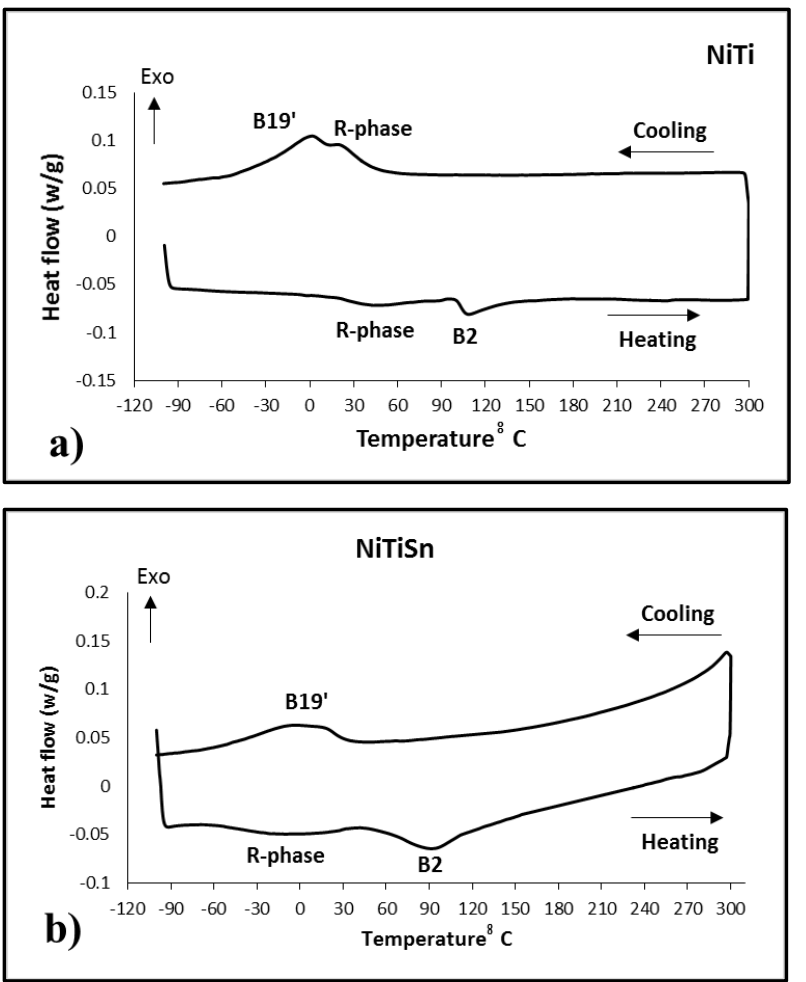

Figure 2: The DSC profile of a) equi-atomic NiTi and b) NiTiSn SMA after heat treatment.

The same behavior was achieved by Jae-hyun $\mathrm{K}$. (16), and one exothermal peak during cooling, which refers to the transformation from austenite to martensite phase, in this alloy can be noticed that there is an obvious reduction in the transformation temperatures comparing with the equiatomic binary NiTi alloy. This result agrees with that achieved by Avery W. Y. (17), he reported that the transformation temperatures decrease when Sn substituted Ni in NiTi shape memory alloys. The transformation peaks for both martensite and austenite transformation become broader with adding Sn element, also thermal hysteresis becomes narrower than in equi-atomic binary Ni-Ti SMA. However, SMAs with large thermal hysteresis, such as equi-atomic $\mathrm{Ni}-\mathrm{Ti}$ alloy, represents good candidates for the application in coupling, such as, pipe and bolted joints, SMAs device extended at low temperatures, the device installed in the mechanical system and heated to produce force (18).

Fig.3 illustrates the patterns of the X-ray diffraction XRD measurement of the heat treated a) equiatomic Ni-Ti SMA and b) NiTiSn SMAs. XRD analysis was accomplished at room temperature in the diffraction angle ranging from $30^{\circ}$ to $80^{\circ}(2 \theta)$ for two samples to identify the crystalline phases.
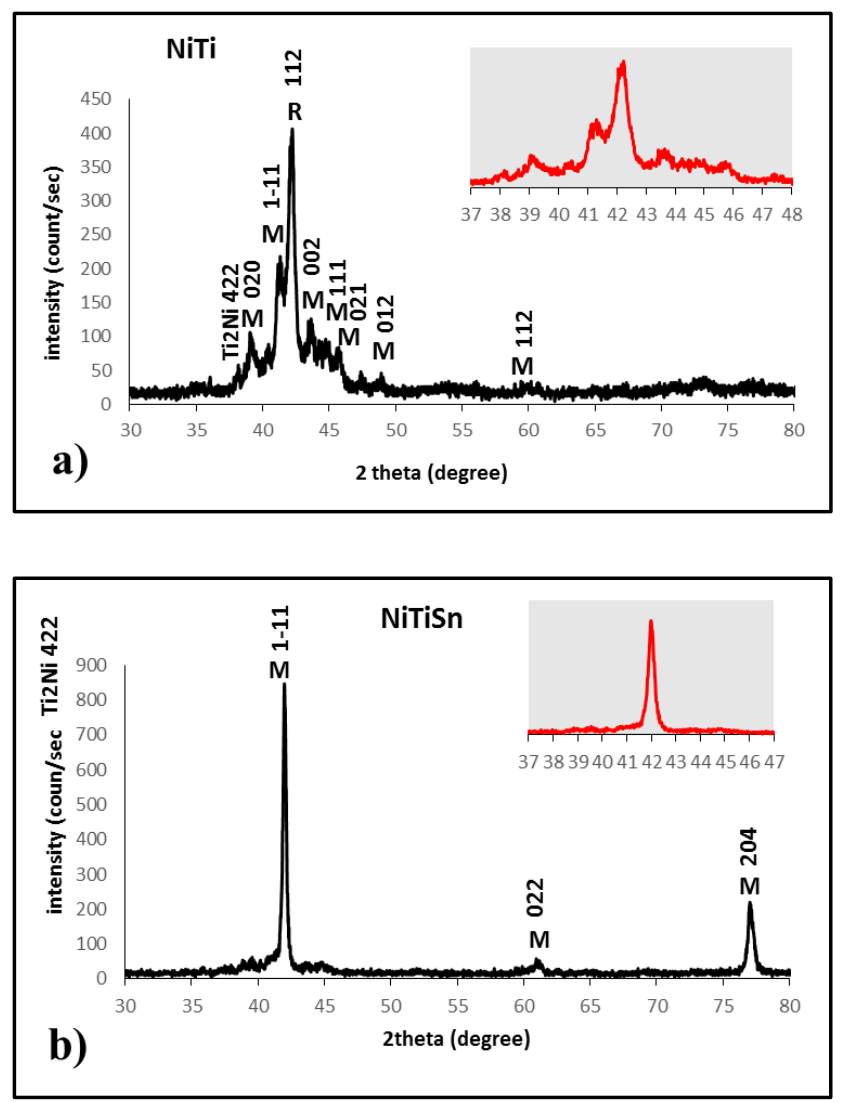

Figure. 3: X-ray diffraction of a) equi-atomic Ni-Ti and b) NiTiSn SMAs after heat treatment at $865^{\circ} \mathrm{C}$ for $15 \mathrm{~min}$.

In equiatomic binary NiTi alloy, a very strong peak (112) of the R-phase is observed. The diffraction reflections from (002), (11 11$),(020),(021),(012)$ and (112) planes of martensitic phase appear, other diffracted peak from (422) have been seen to refer to $\mathrm{Ti}_{2} \mathrm{Ni}$ precipitates phase. In NiTiSn alloy, only diffraction peaks corresponding to the planes (002), $(1 \overline{1} 1)$ and (204) of the martensite phase are 
observed. The diffraction peak of $\mathrm{Ti}_{2} \mathrm{Ni}$ from the plane (442) also observed with very low intensity, this was improved by very small amount of the $\mathrm{Ti}_{2} \mathrm{Ni}$ phase analyzed by the SEM and EDX in Fig.3. NiTiSn XRD patterns are more intense and sharp especially of martensite phase from the plane (1111) than in binary NiTi alloy.

From XRD patterns, it can be seen that the patterns of equi-atomic binary NiTi SMA are broader than NiTiSn patterns, which clearly intimates that the grain structure of equi-atomic binary NiTi SMA is very small. That is the reason for its wider peak than NiTiSn. The patterns of NiTiSn are narrower and sharper than that of equi-atomic binary NiTi SMA, because of the large grain structure of NiTiSn SMA. By measuring the Bragg width of peak at the half of the maximum intensity the grain size can be calculated using Scherrer formula (19).

$$
\tau=\frac{k \lambda}{\beta \cos \theta}
$$

Where $\tau$ represents the grain size $(\mathrm{nm}), \mathrm{k}$ represents the shape factor (0.94), $\lambda$ represents the wavelength of the X-Ray radiation, $\beta$ represents (FWHM) the peak width at half the maximum intensity, and $\theta$ represents the Bragg angle. Average grain size of equi-atomic binary NiTi and NiTiSn SMAs is calculated using Scherer formula is $14.52 \mathrm{~nm}$ and $38.49 \mathrm{~nm}$, respectively.

Fig. 4 shows the microstructure of the a) equiatomic NiTi and b) NiTiSn SMAs by SEM and EDX analysis after heat treatment at $865^{\circ} \mathrm{C}$. The results show that equi-atomic NiTi SMA consists of NiTi matrix phase presented by dashed pointer and precipitates of $\mathrm{Ti}_{2} \mathrm{Ni}$ phase presented by the solid pointer. Table. 2 shows the phases chemical composition existed in the microstructure of two alloys by EDX analysis. The microstructure of the NiTiSn SMA contains NiTiSn matrix-phase (dashed pointer) and precipitates of $\mathrm{Ti}_{2} \mathrm{Ni}$ phase (solid pointer). Also, it can be noticed that the amount of $\mathrm{Ti}_{2} \mathrm{Ni}$ phase in NiTiSn SMA is less than that in equiatomic binary Ni-Ti and smaller in size. This result agrees with that obtained by Jae-hyun K. et al. (14) They reported that with increasing the amount of $\mathrm{Sn}$ addition, the fraction area of the $\mathrm{Ti}_{2} \mathrm{Ni}$ phase decreases. However, in NiTiSn alloy, in an agglomerated non- geometric shape, the $\mathrm{Ti}_{2} \mathrm{Ni}$ phase slightly precipitates, as shown in Fig.4.
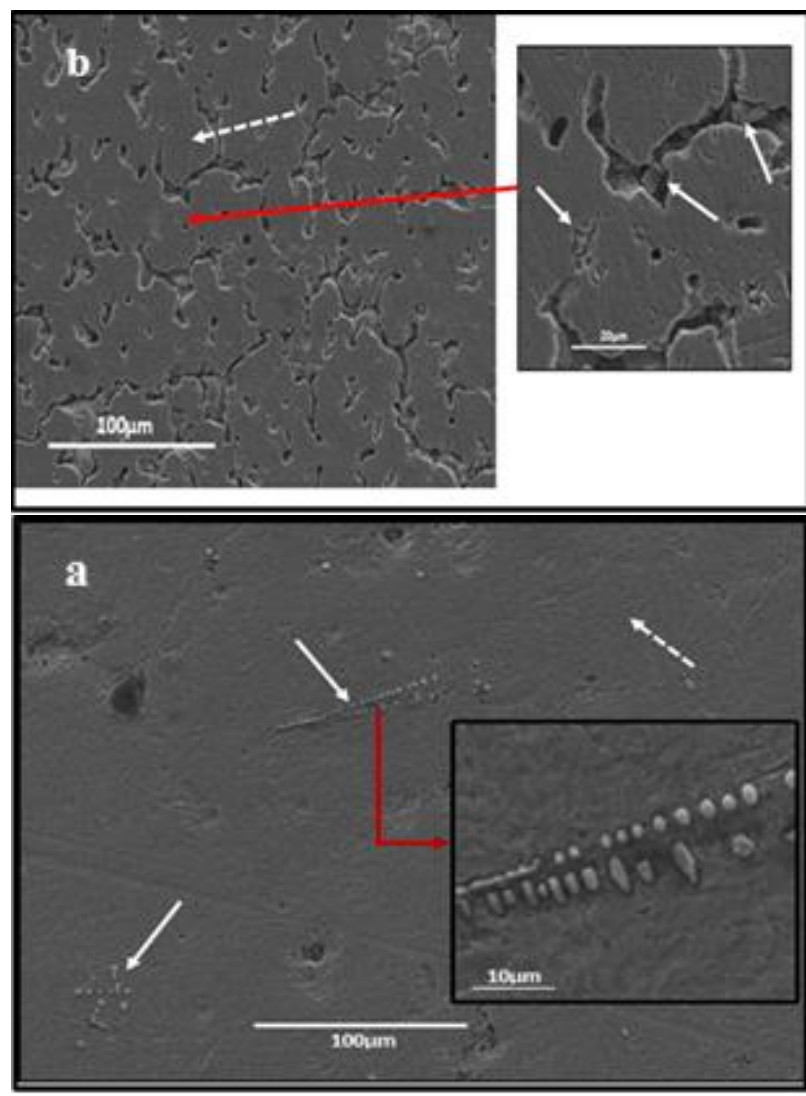

Figure. 4 SEM micrograph of a) equiatomic NiTi alloy, and b) NiTiSn alloy, after heat treatment at $865^{\circ} \mathrm{C}$ for $15 \mathrm{~min}$.

Table. 2 Chemical composition (at.\%) of heat treated NiTi and NiTiSn SMAs at $865^{\circ} \mathrm{C}$ by EDX.

\begin{tabular}{cccc}
\hline Phase & $\mathrm{Ti}$ & $\mathrm{Ni}$ & $\mathrm{Sn}$ \\
\hline NiTi (matrix phase) & 50.2 & 49.8 & 0 \\
NiTiSn (matrix phase) & 50.78 & 47.85 & 1.37 \\
$\mathrm{Ti}_{2} \mathrm{Ni}(0 \%$ at. Sn) & 68.28 & 31.72 & - \\
$\mathrm{Ti}_{2} \mathrm{Ni}$ (2at \% Sn) & 74.48 & 27.94 & 1.85 \\
\hline
\end{tabular}

Figures 5 and 6 show the microstructure of equiatomic NiTi and NiTiSn SMAs before and after heat treatment at $865^{\circ} \mathrm{C}$, determined by the optical microscope. Equiaxed grains rather than dendrites dominate the microstructure of the equiatomic NiTi SMA after heat treatment. The grain size seems to be smaller after heat treatment. NiTiSn SMA shows a dendritic microstructure before and after heat treatment. A great dendritic structure was obtained after heat treatment, and larger grain size. The alloy with $\mathrm{Sn}$ addition contains larger grains size, in comparison with equi-atomic $\mathrm{NiTi}$ alloy. $\mathrm{Ti}_{2} \mathrm{Ni}$ 
phase precipitates on the grain boundaries and in the interior of the grains of equi-atomic NiTi SMA. Solid pointer in Fig. 5 refers to the $\mathrm{Ti}_{2} \mathrm{Ni}$ phase. The matrix NiTi phase is represented by the dashed pointer.

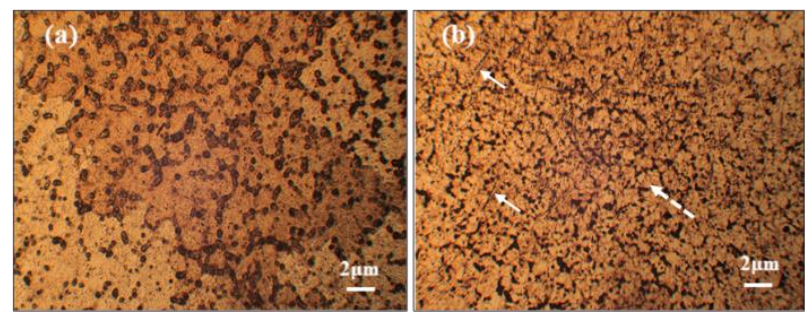

Figure. 5 Optical micrograph of equiatomic NiTi alloy a) before, b) after heat treatment at $865^{\circ} \mathrm{C}$ for $15 \mathrm{~min}$.

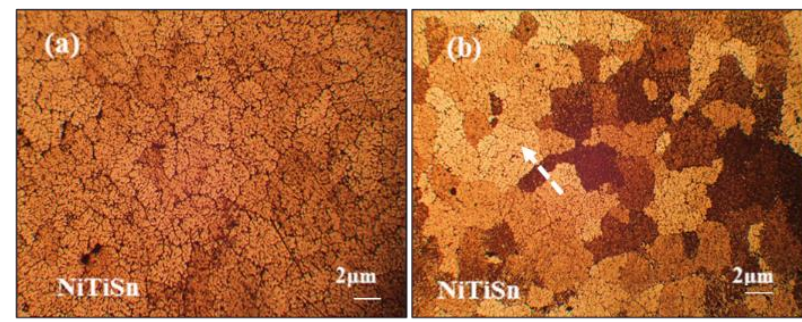

Figure. 6 Optical micrograph of NiTiSn alloy a) before, b) after heat treatment at $865^{\circ} \mathrm{C}$ for 15 min.

Table. 3 Shows the effect of the Sn addition on the micro hardness values of equiatomic NiTi SMA before and after heat treatment. The micro hardness values were determined by taking the average of the seven measurements on each sample. In equiatomic NiTi SMA, it is obviously manifested that there is an appreciable increase in micro hardness after heat treatment because of the solid solution hardening, and also due to the refinement of the grains. The micro hardness of the alloy with adding Sn element increased before heat treatment and decreased after heat treatment in comparison with equiatomic NiTi alloy as can be seen in Table.3. This reduction in micro hardness value can be attributed to significant reduction in $\mathrm{Ti}_{2} \mathrm{Ni}$ hard phase content in NiTiSn alloy (20), as can be seen from SEM/EDS analysis. Also Jai-young J. et al. (21) reported that with alloys that undergo phase transformation $\mathrm{B} 2 \rightarrow \mathrm{R} \rightarrow \mathrm{B} 19^{\prime}$, the microhardness higher than alloys undergoes B2 $\rightarrow$ B19' phase transformation. This behavior can occur because of the hardening of solid solution. So, this can be the reason of the reduction of micro hardness of NiTiSn comparing with that of equiatomic NiTi alloy.
Table. 3 Micro-hardness of equiatomic NiTi and NiTiSn SMAs before and after heat treatment.

\begin{tabular}{ccc}
\hline Alloy & $\begin{array}{c}\text { before heat } \\
\text { treatment }\end{array}$ & $\begin{array}{c}\text { after heat } \\
\text { treatment }\end{array}$ \\
\hline NiTi & 186.06 & 238.74 \\
NiTiSn & 242 & 202 \\
\hline
\end{tabular}

\section{Conclusions}

Adding tin ( $\mathrm{Sn}$ ) element to $\mathrm{Ni}-\mathrm{Ti}$ shape memory alloy leads to the reduction in the transformation temperatures. SEM and EDX analyses reveal that with the addition of tin $(\mathrm{Sn})$ element, the size and amount of $\mathrm{Ti}_{2} \mathrm{~N}$ phase decreases in the matrix phase. Optical photographs show that the dendritic structure becomes greater after heat treatment, also the X-ray analysis and by using scherrer equation reveal that the NiTiSn SMA has a grain size greater than equiatomic Ni-Ti SMA. In NiTiSn alloy, the micro hardness decreases after heat treatment in comparison with equi-atomic NiTi alloy. This can be attributed to decreasing the amount of $\mathrm{Ti}_{2} \mathrm{~N}$ hard phase, and also, because of the dendritic structure which becomes greater after heat treatment. Thermal hysteresis decreases with adding tin (Sn) element to NiTi SMA. However, SMAs with large thermal hysteresis, such as equiatomic Ni-Ti SMA, can be used in candidates coupling application, like, pipe-joints and boltedjoints.

Conflicts of Interest: The authors declare no conflict of interest.

\section{Authors' declaration:}

- Conflicts of Interest: None.

- We hereby confirm that all the Figures and Tables in the manuscript are mine ours. Besides, the Figures and images, which are not mine ours, have been given the permission for re-publication attached with the manuscript.

- The author has signed an animal welfare statement.

- Ethical Clearance: The project was approved by the local ethical committee in University of Technology .

\section{References}

1. Elahinia MH, Hashemi M, Tabesh M, Bhaduri SB. Manufacturing and processing of NiTi implants: A review. Prog mater sci. 2012 Jun 1; 57(5):911-46.

2. Ohkata I, Tsuchiya K, Miyazaki, S. Shape Memory and Superelastic Alloys: Applications and Technologies, Yamauchi K, Ed.; Reprint Edition; Woodhead Publishing: Cambridge, UK, 2016; ISBN 978-0-08-101701-2. 
3. Otsuka K, Ren X. Physical metallurgy of Ti-Ni-based shape memory alloys. Prog mater sci. 2005 Jul 1; 50(5):511-678.

4. Li P, Jia Y, Wang Y, Li Q, Meng F, He Z. Effect of Fe Addition on Microstructure and Mechanical Properties of As-cast Ti49Ni51 Alloy. Materials. 2019 Jan; 12(19):3114.

5. Kök M, Ateş G. The effect of addition of various elements on properties of NiTi-based shape memory alloys for biomedical application. EPJ Plus. 2017 Apr $1 ; 132(4): 185$.

6. Santosh S, Sampath V. Effect of Ternary Addition of Cobalt on Shape Memory Characteristics of Ni-Ti Alloys. T Indian I Metals. 2019 Jun 1; 72(6):1481-4.

7. Kim YW, Jo BG, Young S, Nam TH. Shape memory characteristics of porous Ti-Ni-Mo alloys prepared by solid state sintering. Mate Res Bull. 2016 Oct 1; 82:459.

8. Wang X, Kustov S, Verlinden B, Van Humbeeck J. Fundamental development on utilizing the R-phase transformation in NiTi shape memory alloys. Shap. Mem. Superelasticity. 2015 Jun 1; 1(2):231-9.

9. Ruiz-Larrea I, López-Echarri A, Breczewski T, López G, Lopez-Ferreño I, Nó M, et al. The Influence of Thermal History on the Multistage Transformation of NiTi Shape-Memory Alloys. Metals. 2018 Apr; 8(4):246.

10. Wang X, Verlinden B, Van Humbeeck J. Effect of aging temperature and time on the transformation behavior of a Ti-50.8 at. \% Ni alloy with small grains. MaterToday: Proc. 2015 Jan 1; 2:S565-8.

11. Zhang YQ, Jiang SY, Zhu XM, Zhao YN, Liang YL, Dong SU. Influence of Fe addition on phase transformation behavior of NiTi shape memory alloy. T Nonferr Metal Soc. 2017 Jul 1; 27(7):1580-7.
12. Frenzel J, Wieczorek A, Opahle I, Maab B, Drautz R, Eggeler G. On the effect of alloy composition on martensite start temperatures and latent heats in Ni-Ti-based shape memory alloys. Acta Mater. 2015 May 15; 90:213-31.

13. Kurita T, Matsumoto H, Sakamoto K, Tanji K, Abe $H$. Effect of aluminum addition on the transformation of NiTi alloy. J alloy compd. 2005 Jun $21 ; 396(1-2): 193-6$.

14. Kim JH, Jung KT, Noh JP, Cho GB, Miyazaki S, Nam TH. Martensitic transformation behavior of Ti-Ni-Sn alloys. J alloy compd. 2013 Nov 15; 577:S200-4.

15. Nayan N, Saikrishna CN, Ramaiah KV, Bhaumik SK, Nair KS, Mittal MC. Vacuum induction melting of NiTi shape memory alloys in graphite crucible. Mat Sci Eng: A. 2007 Sep 15; 465(1-2):44-8.

16. Kim JH, Choi HJ, Kim MS, Miyazaki S, Kim YW, Chun BS, et al. Crystallization and martensitic transformation behavior of $\mathrm{Ti}-\mathrm{Ni}-\mathrm{Sn}$ alloy ribbons. Intermetallics. 2012 Nov 1; 30:51-6.

17. Young AW, Torgerson T, Ley NA, Gomez K, Benafan O, Young ML. Effects of Sn Addition on NiTi Shape Memory Alloys. Shape Memory and Superelasticity. 2019 Mar 15; 5(1):125-35.

18. Antonios C, Inman DJ, Smaili A. Experimental and theoretical behavior of self-healing bolted joints. $\mathrm{J}$ Intel Mat Syst Str. 2006 Jun; 17(6):499-509.

19. Suryanarayana C. Mechanical alloying and milling. Prog mater sci. 2001 Jan 1;46(1-2):1-84.

20. El-Bagoury N. Microstructure and martensitic transformation and mechanical properties of cast $\mathrm{Ni}$ rich NiTiCo shape memory alloys. Mater Sci Techlond. 2014 Nov 1; 30(14):1795-800.

21. Jang JY, Chun SJ, Kim NS, Cho JW, Kim JH, Yeom JT, et al. Martensitic transformation behavior in Ti-Ni-X (Ag, In, Sn, Sb, Te, Tl, Pb, Bi) ternary alloys. Mater Res Bull. 2013 Dec 1; 48(12):5064-9.

\section{تأثثر اضافة القصدير على سلوك التحول الطوري في سبيكة النيكل تيتانيوم المتساوية التركيب المتذكرة الشكل
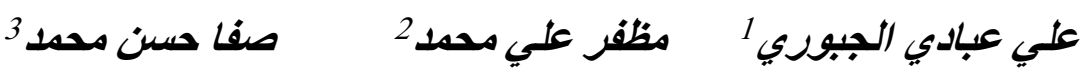

1,2,3 قسم العلوم التطبيقية/ الجامعة التكنولوجية/ بغداد/ العراق

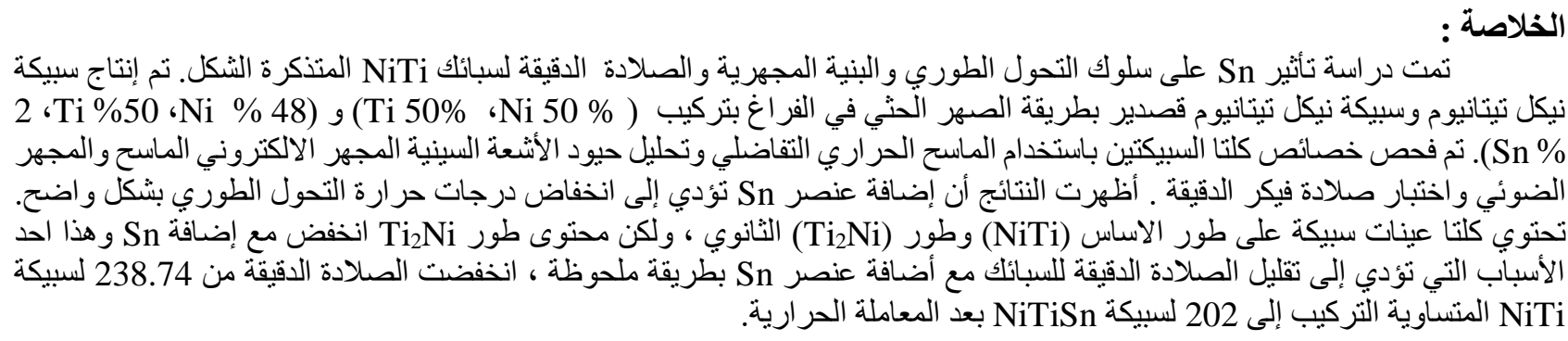

الكلمات المفتاحية: الماسح الحر اري التفاضلي، سبيكة نيكل تيتانيوم ، سبيكة نيكل تيتانيوم قصدير، السبائك المتذكرة الثكل. 